\title{
TECHNICAL EFFICIENCY ON INDONESIAN MAIZE PRODUCTION: FRONTIER STOCHASTIC ANALYSIS (SFA) AND DATA ENVELOPMENT ANALYSIS (DEA) APPROACH
}

\author{
Asmara R. ${ }^{*}$, Hanani N., Syafrial S., Mustadjab M.M. \\ Faculty of Agriculture, University of Brawijaya, Indonesia \\ *E-mail: rosihan@ymail.com
}

\begin{abstract}
In order to achieve maize self-sufficiency in Indonesia, efficiency ought to be increased. Therefore, this study is aimed to assess technical efficiency of wide range of farmers. It is done in order to formulate a policy to increase the productivity of maize. The study was conducted in regions that produce maize. Sample farmers were determined to be nonproportionate stratified random sampling by land class strata, namely wetland and dry land. Analysis methods utilized in this research are Data Envelopment Analysis (DEA) and Analysis Frontier Stochastic (SFA). As for assessment of factors affecting technical efficiency analysis, Tobit regression models is utilized. The results of this research exhibits that the technical efficiency (TE) utilizing SFA approach gained an average of 0.78 . On the other hand, the DEA approach obtained an average of 0.9. SFA approach exhibits lower TE value and evenly distributed among farmers compared to DEA approach, where no value is less than 0.6. Factors affecting TE are education, land ownership, extension frequency, and demonstration plot. Based on DEA approach also obtained the fact that most farmers are on the conditions of increasing returns to scale.
\end{abstract}

\section{KEY WORDS}

Technical efficiency, maize, data envelopment analysis, stochastic frontier analysis.

Indonesian agricultural sector has a substantial contribution to the national income (GDP) and employs labor. The government currently endeavors in increasing agricultural production, especially food crops. Some of the agricultural productions could not meet increasing demand and had to be fulfilled by importing agricultural products. Therefore, for strategic agricultural commodities, the government tried to invoke self-sufficiency with intention of meeting consumption demand and increase farmers' income at the same time.

Maize is considered as strategic food commodity as it is produced by majority of Indonesian farmers. Indonesia is included in maize producing countries; however, Indonesia imports maize at the same time which is caused by high consumption of maize. Maize is used for human consumption or animal feed manufacturing. Based on Direktorat Tanaman Pangan Kementerian Pertanian (2013) data, maize demand in Indonesia continues to increase with the rate of 5.41 percent each year compared to 3.21 percent production increase rate. Due to forementioned issue, the government endeavor to apply maize selfsufficiency policy. The policy is made by the government in line with the increasing maize consumption.

In order to achieve maize self-sufficiency, efforts could be directed in increasing production, either through increased productivity and expansion. Increased production should also be followed by competitiveness improvement, ensuring that the product are capable to compete in domestic and international markets. Mentioned objectives could be achieved by increasing farming efficiency. One method to improve farming efficiency is by utilizing farm inputs optimally. Concerning this current issue, it is important to research on farmers' productive performance as well as identify factors that affect productivity. This study aims to estimate the technical efficiency of a wide range of farmers, in order to formulate policies for enhancing maize productivity. 


\section{MATERIALS AND METHODS OF RESEARCH}

The study was conducted in East Java province by taking random samples in Tuban district. Village chosen as sample was selected randomly from villages in maize production areas. Sample farmers taken were determined using non proportionate stratified random sampling, by dividing land class strata, namely wet land and dry land.

There are two commonly used research methods, which involved Data Envelopment Analysis (DEA) and Analysis Frontier Stochastic (SFA). Technical efficiency obtained from the two approaches are examined in order to obtain comparable information to determine which method is more suitable for the Indonesian maize agriculture technical efficiency analysis. Analysis Frontier Stochastic used in research refers to the approach mentioned by Aigner et.al., (1977). The general form of stochastic frontier production function is as follows:

$$
Y=f(X i ; \beta)+\varepsilon, i=1,2 \ldots n
$$

$Y$ represents output farming, while $X i$ is farming input vector, $\varepsilon$ is composite error, $\varepsilon=V-U$. $V$ is a random variable that is assumed to be $N \sim(0, \delta 2 V)$ which exhibits error component of stochastic effects that cannot be controlled by farmers such as the weather and other similar issues. Random variable $U$ is non-negative random which shows inefficiency of farming (Coelli et al., 2005). $U$ is assumed independent from V. Parameter $\beta$ serves to be assessed. Model used follows coob-douglas stochastic frontier production function.

$$
\operatorname{LnY}=\beta_{0}+\beta_{1} \operatorname{LnX} 1+\beta_{2} \operatorname{LnX} 2+\beta_{3} \operatorname{LnX} 3+\beta_{4} \operatorname{LnX} 4+\beta_{5} \operatorname{LnX} 5+\beta_{6} \operatorname{LnX} 6+\left(v_{i}-u_{i}\right)
$$

$\mathrm{Y}$ represents the maize total production, $\mathrm{X} 1, \mathrm{X} 2, \mathrm{X} 3, \mathrm{X} 4, \mathrm{X} 5$, and $\mathrm{X} 6$ consecutively shows seeds, urea, Phoska fertilizers, manure, pesticides, energy. Parameter estimation is done using the estimation method MLE (Maximum Likelihood Estimate). Measuring the level of technical efficiency (TE) in the study conducted by the following calculation:

$$
\mathrm{TE}_{\mathrm{it}}=\exp \left(-\mathrm{u}_{\mathrm{it}}\right)
$$

Data Envelopment Analysis (DEA) in this study using the approach developed by Charnes el al. Rhodes (1978). In addition to compare efficiency across the Unit Pengambilan Keputusan (Decision Making Unit) among farmers, used to compare the efficiency in the whole company. It is assumed that corn farmers to produce corn quantity (yi) using multiple inputs (xi), seed, labor, fertilizer, and pesticides. To determine the technical efficiency for farmers to $i$, then the liner program used is as follows:

$$
\begin{gathered}
\text { Maximize }_{\theta \lambda} \theta \\
\text { Subject to: } \\
-\theta y i+Y \lambda \geq 0 \\
X i-X \lambda \geq 0 \\
N 1^{\prime} \lambda=1 \\
\lambda \geq 0
\end{gathered}
$$

$\theta$ represents technical efficiency (TE) score of sample of farmers with value between 0 and 1. yi represents maize total production from farmers to I, xi represents $\mathrm{Nx} 1$ vector which is number of inputs from farmers to $\mathrm{i}, \mathrm{Y}$ is a vector that represents $1 \mathrm{xM}$ for production, $\mathrm{N}$ is $\mathrm{NxM}$ matrix of total production inputs used in the country, $\lambda$ is the vector MX1 of weight and $\theta$ is a scalar. Empirically, programming linear model above is specified by constant returns to scale (CRS). Returns to scale variable (VRS) equation (4) are added constraints, $N 1^{\prime} \lambda=1$. By ascertaining technical efficiency using CRS and VRS, efficiency of the effort scale will be found. Effort Scale efficiency (SE) could be formulated as follows:

$$
S E_{i}=\theta_{i}^{C R S} / \theta_{i}^{\text {VRS }}
$$


As for ascertaining factors affecting both technical efficiency gained through SFA and DEA will be analyzed utilizing Tobit regression model, which is formulated as follows:

$$
T E=\alpha_{0}+\alpha_{1} V_{1}+\alpha_{2} V_{2}+\alpha_{3} V_{3}+\alpha_{4} V_{4}+\alpha_{5} V_{5}+\ldots \ldots+\alpha_{10} V_{10}+\mu_{i}
$$

TE represents level of technical efficiency, while Vi represents the factors affecting technical efficiency. Vi consists of 10 variables, which are: age, sex farmers, education, Occupation, family size, land size, land ownership, variety, counseling frequency, farm demonstration plots. The model is estimated using maximum likelihood estimation method.

\section{RESULTS AND DISCUSSION}

The results of production factors based on cobb-douglas stochastic frontier function of maize production is exhibited in Table 1. Production factors that significantly affect maize production are as follows: seeds, Phonska fertilizer, and manure, while the urea fertilizer, pesticides and labor had no significant effect.

Table 1 - Cobb-Douglas Stochastic Frontier Maize Production Estimation Result Function

\begin{tabular}{|c|c|c|c|}
\hline \multirow{2}{*}{ Variable } & \multicolumn{3}{|c|}{ MLE (Maximum Likelihood Estimate) } \\
\hline & Coefficient & Standard-error & t-hitung \\
\hline Intercept & 3.318 & 0.881 & $3.766^{* *}$ \\
\hline $\mathrm{X}_{1}$ (Seed) & 0.665 & 0.256 & $2.596^{*}$ \\
\hline $\mathrm{X}_{2}$ (Urea Fertilizer) & -0.070 & 0.107 & -0.656 \\
\hline $\mathrm{X}_{3}$ (Phonska Fertilizer) & 0.335 & 0.101 & $3.335^{\star *}$ \\
\hline $\mathrm{X}_{4}$ (Manure) & 0.285 & 0.096 & $2.976^{* *}$ \\
\hline $\mathrm{X}_{5}$ (Pesticide) & -0.141 & 0.115 & -1.230 \\
\hline $\mathrm{X}_{6}$ (Labor) & 0.030 & 0.108 & 0.280 \\
\hline Sigma-squared & 0.124 & 0.038 & $3.297^{* *}$ \\
\hline Gamma & 0.935 & 0.082 & $11.443^{* *}$ \\
\hline Log Likelihood Function & & & 7.619 \\
\hline LR test & & & 3.414 \\
\hline
\end{tabular}

Note $:{ }^{* *}$ sig. at $\alpha=0.01 ;{ }^{*}$ sig. at $\alpha=0.01$

Using third formula (3) will allow finding technical efficiency of each farmer (Figure 1) by utilizing SFA approach. On the other hand, technical efficiency estimation based on DEA approach is presented in Figure 2. The difference between technical efficiency between SFA compared to DEA approach will be exhibited in (Figure 3).

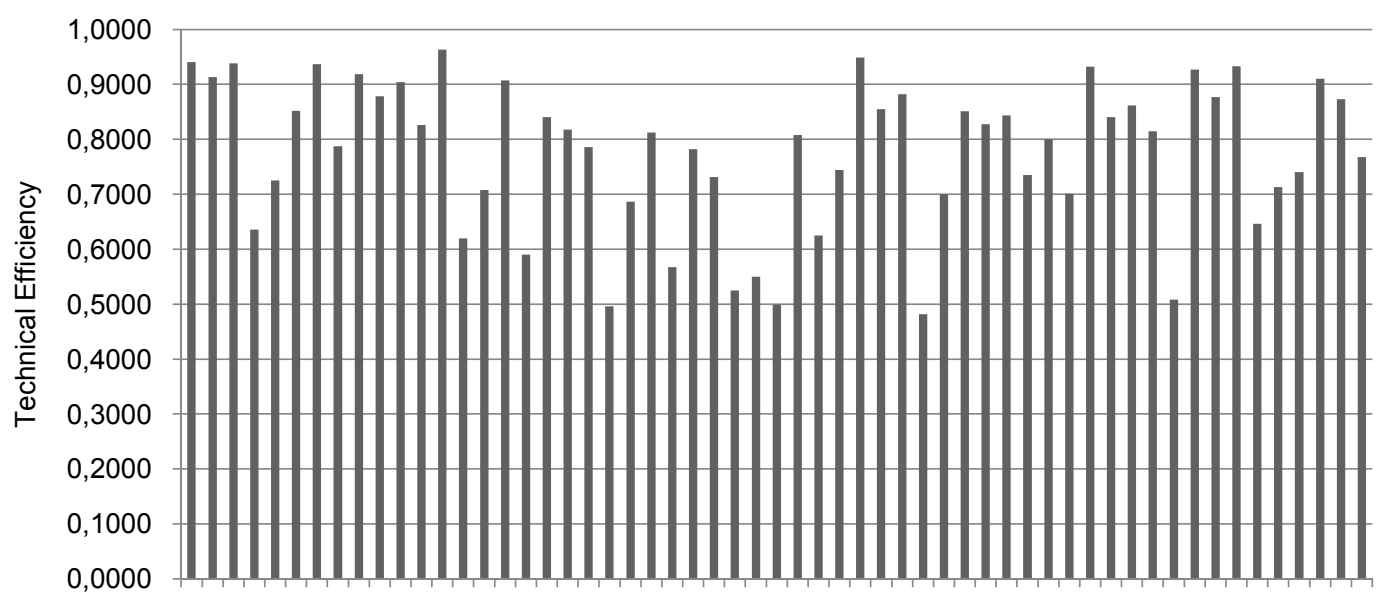

$1 \quad 3 \quad 5 \quad 7 \quad 9 \quad 111315171921232527293133353739414345474951535557$

Farmer

Figure 1 - Technical Efficiency Distribution Based on SFA Approach 


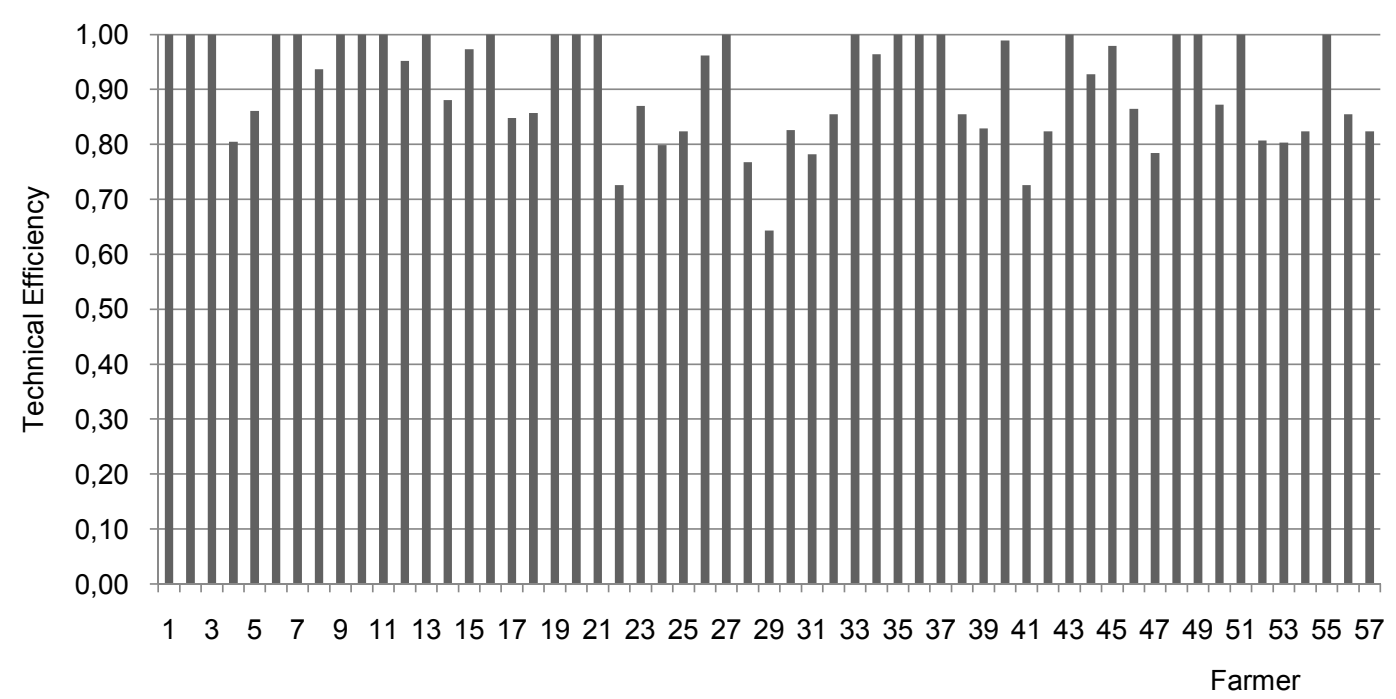

Figure 2 - Technical Efficiency Distribution Based on DEA Approach

The technical efficiency of the SFA approach gained an average of 0.78 with range of 0.48-0.96, while the DEA 0.91 with range of 0.64-1. TE on the SFA value distribution more evenly than the DEA. Result of this indicates that SFA approach is a better option to be used to enhance maize farming technical efficiency in Indonesia.

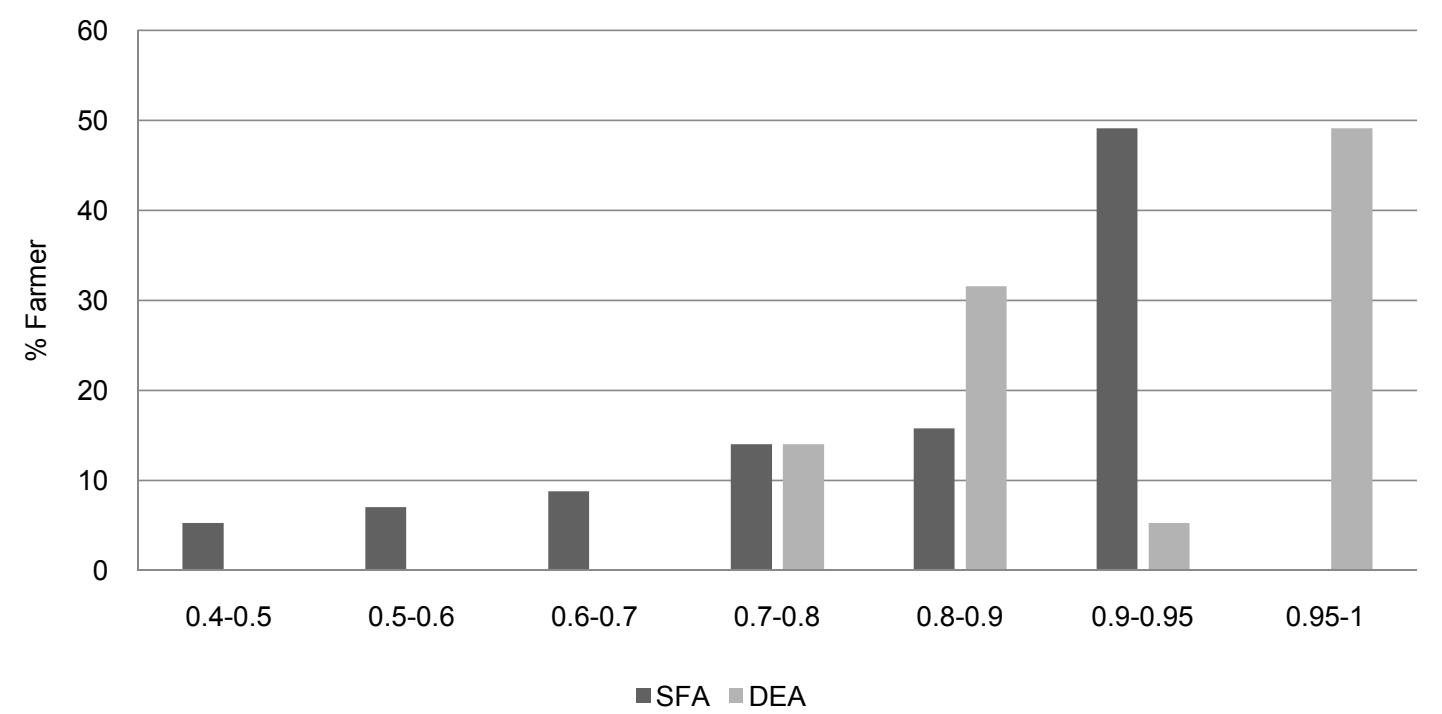

Figure 3 - Technical Efficiency Comparison Based on SFA and DEA Approach

In general, maize farmers are not technically efficient because they excessively peruse inputs. DEA analysis results showed no slack fulfillment with zero values for every agriculture variables used by majority of farmers. The use of urea fertilizer, pesticides and labor usage is excessively used (Table 2 ).

Table 2 - Maize Production Input Slack Value

\begin{tabular}{lcc}
\hline \multicolumn{1}{c}{ Input of Production } & Slack Average & Farmer Excess Frequency \\
\hline Seed $(\mathrm{kg})$ & 0.29 & 9 \\
Urea Fertilizer $(\mathrm{kg})$ & 43.297 & 25 \\
Phonska Fertilizer $(\mathrm{kg})$ & 6.611 & 8 \\
Manure (kg) & 104.011 & 14 \\
Pesticide (It) & 0.459 & 26 \\
Labor (man/day) & 67.191 & 30 \\
\hline
\end{tabular}


Based on return to scale condition, most Indonesian maize farmers are in conditions of increasing returns to scale (IRS). A total of $66.67 \%$ with IRs while the CRS (constant return to scale) by $28 \%$ and $5 \%$ were in state of DRS (decreasing return to scale) (Figure 4).

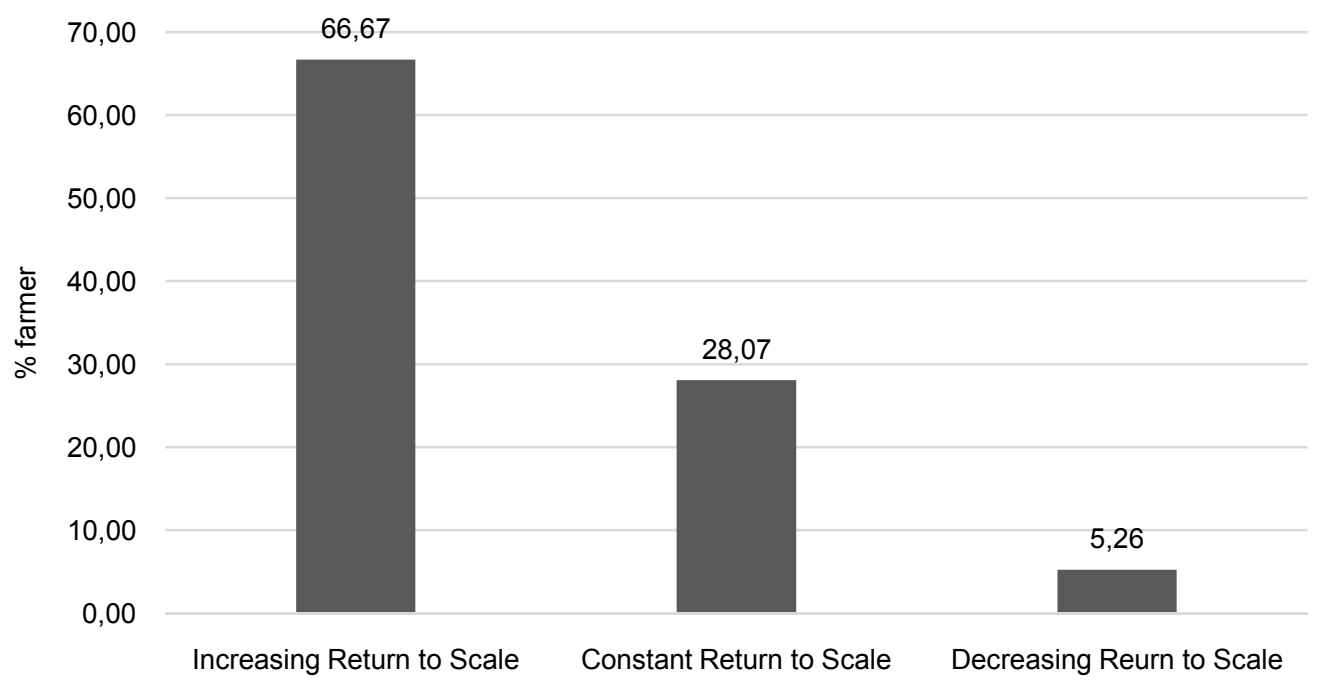

Figure 4 - Farmer Distribution Based on Maize Agriculture Return to Scale

Factors influencing Technical Efficiency (TE) in this study utilized TE generated by SFA and DEA approach. Based on log likelihood value, SFA models appear higher than the DEA. This shows that the SFA is a better approach due to the TE variations which are described from independent modifiers compared to DEA models. Results of the analysis exhibits the factors affecting TE are education, land ownership, counseling frequency, and demonstration plot (Table 3).

Table 3 - Factors Affecting Estimation Maize Agriculture Technical Efficiency Result

\begin{tabular}{|c|c|c|c|c|c|c|c|c|}
\hline \multirow{2}{*}{ SFA } & \multicolumn{4}{|c|}{ SFA } & \multicolumn{4}{|c|}{ DEA } \\
\hline & Coef. & Std. Err. & $\mathrm{t}$ & $\mathrm{P}>\mathrm{t}$ & Coef. & Std. Err. & $\mathrm{t}$ & $P>t$ \\
\hline Intercept & 0.5991838 & 0.0476 & 12.59 & 0.000 & 0.805624 & 0.06865 & 11.740 & 0.000 \\
\hline Age & 0.0006313 & 0.000711 & 0.89 & 0.379 & -0.00033 & 0.00103 & -0.320 & 0.749 \\
\hline Sex & 0.0187172 & 0.017023 & 1.10 & 0.277 & -0.00887 & 0.02447 & -0.360 & 0.719 \\
\hline Education & 0.0209738 & 0.003498 & 6.00 & 0.000 & 0.002077 & 0.00504 & 0.410 & 0.682 \\
\hline Occupation & -0.0028687 & 0.032648 & -0.09 & 0.930 & 0.052169 & 0.04707 & 1.110 & 0.273 \\
\hline Family size & -0.0034263 & 0.006012 & -0.57 & 0.571 & 0.008436 & 0.00865 & 0.980 & 0.334 \\
\hline Land size & 0.0147504 & 0.016484 & 0.89 & 0.375 & 0.063596 & 0.02379 & 2.670 & 0.010 \\
\hline Land ownership & -0.0519685 & 0.01649 & -3.15 & 0.003 & -0.04237 & 0.02378 & -1.780 & 0.081 \\
\hline Variety & -0.0139887 & 0.016708 & -0.84 & 0.407 & -0.02416 & 0.02408 & -1.000 & 0.321 \\
\hline Counseling & 0.0260296 & 0.004477 & 5.81 & 0.000 & 0.010158 & 0.00646 & 1.570 & 0.122 \\
\hline Dem Plot & 0.04443 & 0.023469 & 1.89 & 0.065 & -0.01484 & 0.03382 & -0.440 & 0.663 \\
\hline sigma Squared & 0.0522445 & 0.004959 & & & 0.075367 & 0.00717 & & \\
\hline Log likelihood & & & & 49814 & & & & 19518 \\
\hline LR chi2(10) & & & & 107.09 & & & & 27.49 \\
\hline Prob > chi2 & & & & 0.0000 & & & & 0.0022 \\
\hline
\end{tabular}

TE will increase according to farmers' education level. Unfortunately maize farmers land lord's TE is lower compared to tenant farmers. Enhancing TE can be done through by increasing demonstration plot and counseling frequency.

\section{CONCLUSION}

Value of technical efficiency (TE) on SFA approach is higher and evenly distributed compared to DEA. SFA approach gained an average of 0.78 in $0.48-0.96$ range. On the other hands, DEA resulted in average value of 0.91 in range of $0.64-1$. These results indicate 
that SFA approach is a better option to optimize TE for maize agriculture in Indonesia. Farmers who are technically perform under low efficiency due to excessive use of inputs. The use of urea fertilizer, pesticides and labor usage is excessively used by farmers. Based on return to scale aspect, farmers generally are in the condition of increasing returns to scale (IRS).

Factors affecting TE are education, land ownership, counseling frequency, and demonstration plot. Efforts to increase maize production by increasing efficiency is possible in Indonesia because of the level of efficiency achieved hasn't reached full potential. It can be done by prioritizing education and demonstration plots on farmers who have low level of education.

\section{REFERENCES}

1. Siregar,M and Sumaryanto. 2003. Estimating Soybean Production Efficiency In Irrigated Area Of Brantas River Basin. Indonesia Journal of Agricultural Science. 4(2). 33-39

2. Ajao, AO, Ogunniy, LT, and A. A. Adepoju. 2012. Economic Efficiency of Soybean Production in Ogo-Oluwa Local Government Area of Oyo State, Nigeria. American Journal of Experimental AgricultureVol 2(4): 667-679

3. Etwire, P.M Martey, E. \& W.Dogb. 2013. Technical Efficiency of Soybean Farms and Its Determinants in Saboba and Chereponi Districts of Northern Ghana: A Stochastic Frontier Approach. Sustainable Agriculture Research; Vol. 2, (4); 106-116

4. Yegon, PK, Kibet, L.K and J.K Lagat. Determinants of Technical Efficiency in smallholder Soybean Production in Bomet District, Kenya. Journal of Development and Agricultyural Economic. Vol 7 (5), 190-194

5. Kibaara, B.W. 2005. Technical Efficiency in Kenyan's Maize Production: An Application Of The Stochastic Frontier Approach [Thesis]. Colorado (US): Colorado State University Fort Collins.

6. Komleh .S.H. , Omid. M, A Keyhani. 2011. Study On Energy Use Pattern And Efficiency Of Corn Silage In Iran By Using Data Envelopment Analysis (DEA) Technique. International Journal Of Environmental Sciences. 1(6): 1094-1106

7. Abatania, Hailu. A and A.W. Mugera. 2011. Analysis of farm household technical efficiency in Northern Ghana using bootstrap DEA. Paper presented at the 56th annual conference of the Australian Agricultural and Resource Economics Society. The Esplanade Hotel, Fremantle WA, 7-10 February 2012

8. Ngeno, V, Mengist, BK, Lanagat, Nyangweso, Serem and MJ. Kipsat. 2012. Measuring Technical Efficiency Among Maize Farmer in Kenya. Agricultural Journal 7(2): 106-110

9. Orhun, G.U and E Orhun. 2013. Efficiency Analysis of Silage Maize Production in the Province of Canakkale, Turki. Asian Journal of Agricultural Extension, Economics \& Sociology 2(2), 140-151

10. Xiao, J. 2011. An Analysis on Technical Efficiency of Paddy Production in China. Asian Social Science. 6 (70: 170-176

11. M. Umanath, M \& D. D Rajasekar. 2013. Estimation of Technical, Scale and Economic Efficiency of Paddy Farms: A Data Envelopment Analysis Approach. Journal of Agricultural Science. V (8): 243-251

12. Vu, L.K. 2009. Efficiency of Rice Farming Households in Vietnam: A DEA with Bootstrap and Stochastic Frontier Application. Department of Applied Economics, University of Minnesota

13. Kiatpathomchai, S., Schmitz, PM and S. Thongrak 2009. Technical efficiency improvement of rice farming in southern Thailand. Paper prepared for presentation at the International Association of Agricultural Economists Conference, Beijing, China, August 16-22, 2009

14. ASEAN Food Security Information System (AFSIS), 2016. Statistic. http://www.afsisnc.org/statistics

15. Food and Agriculture Organization (FAO). 2016. Production and Trade. Faostat.org. http://www.fao.org 